Thomas Mormann*

\title{
Two Kindred Neo-Kantian Philosophies of Science: Pap's The A Priori in Physical Theory and Cassirer's Determinism and Indeterminism in Modern Physics
}

https://doi.org/10.1515/jtph-2021-0001

Published online m.

Abstract: The main thesis of this paper is that Pap's The Functional A Priori in Physical Theory and Cassirer's Determinism and Indeterminism in Modern Physics may be conceived as two kindred accounts of a late Neo-Kantian philosophy of science. They elucidate and clarify each other mutually by elaborating conceptual possibilities and pointing out affinities of neo-Kantian ideas with other currents of 20th century's philosophy of science, namely, pragmatism, conventionalism, and logical empiricism. Taking into account these facts, it seems not too far fetched to conjecture that under more favorable circumstances Pap could have served as a mediator between the "analytic" and "continental" tradition thereby overcoming the dogmatic dualism of these two philosophical currents that has characterized philosophy in the second half the 20th century.

Keywords: neo-Kantianism, pragmatism, logical empiricism, Arthur Pap, Ernst Cassirer

\section{Introduction}

The main thesis of this paper is that Pap's The A Priori in Physical Theory (Pap 1946, henceforth FAP) and Cassirer's Determinism and Indeterminism in Modern Physics (Cassirer 1937, henceforth DI) may be conceived as two kindred accounts of a late Neo-Kantian philosophy of science. They elucidate and clarify each other mutually by elaborating conceptual possibilities and pointing out affinities of neo-Kantian ideas with other currents of 20th century's philosophy of science, namely, pragmatism, conventionalism, and logical empiricism.

\footnotetext{
*Corresponding author: Thomas Mormann, Faculty of Philosophy and Education Sciences, University of the Basque Country, Avenida de Tolosa 70, Donostia 20018, Spain,

E-mail: thomasarnold.mormann@ehu.eus
} 
In his early papers Pap heavily drew on Cassirer's DI. More precisely, Pap's central concept of the functional a priori can be shown to be closely related to the concept of "principles" that plays a central role in DI. ${ }^{1}$ Thus, in order to understand Pap's "functional a priori" one has to understand the role of "principles" in DI, or so I want to argue. The origins of Pap's theory of the "functional a priori" in FAP can be found in his early papers in which Cassirer's influence is most clearly visible (cf. Pap 1943, p. 44).

An expedient point of departure is David Stump's recent claim that for understanding Pap's philosophy of science

Neo-Kantianism is important because it formed a context for the work of the Pragmatists, the Vienna Circle and to Poincaré's work. It grounds the focus on the human element of knowledge and provides the basic distinctions between the $a$ priori and the empirical and the analytic and synthetic. (Stump 2015, p. 104)

The thesis that Neo-Kantianism is a convenient "synthetizing" context for the project of a comprehensive philosophy of science that takes into account aspects of pragmatism, logical empiricism, and conventionalism is certainly apt for elucidating Pap's thought. This thesis, however, would have hardly been endorsed by many pragmatists, Vienna Circle logical empiricists, or the conventionalists: American pragmatists such as Dewey, James, or C.I. Lewis never paid much attention to German Neo-Kantianism, the members of the Vienna Circle flatly denied that anything could be learned from Neo-Kantian "school philosophy", and conventionalists such as Poincaré had not much interest to delve in the philosophical subtleties of Neo-Kantianism. On the other hand, the leading Neo-Kantian philosopher Cassirer did pay serious attention to then

1 DI was not translated into English before 1956. Together with Cassirer's untimely death in 1945 and the general eclipse of neo-Kantianism after 1945 this may have contributed to the fact that the Neo-Kantian aspects of Pap's philosophy were ignored or at least severely underestimated in the Anglo-Saxon philosophical scene in the following decades. Another factor that may have contributed to the eclipse of the neo-Kantian aspects of Pap's thought may be that later in his philosophical career Pap attempted to play down (or even deny) any non-analytic neo-Kantian influence on his thought. Nevertheless, it seems, he never succeeded to be fully recognized as a mainstream analytic philosopher. This is evidenced already by browsing through many of the reviews that his last two books Semantics and Necessary Truth: An Inquiry into the Foundations of Analytic Philosophy (Pap 1958) and An Introduction into the Philosophy of Science (Pap 1962) received. See Section 2 of this paper for some more detailed remarks on this issue. Be this as it may, the present paper is primarily on Pap's early philosophy. It does not pretend to cover this author's entire philosophical evolution. 
contemporary rival currents of philosophy such as pragmatism, conventionalism, and logical empiricism. ${ }^{2}$

In order to understand the relevance of Cassirer's Neo-Kantianism for Pap it is necessary to go beyond the general characterization of Neo-Kantianism as a current of philosophy of science that "grounds the focus on the human element of knowledge". Indeed, the specific source for the importance of Neo-Kantianism on Pap's philosophy can be localized rather precisely, or so I want to argue in this paper. To be precise, the main source of inspiration for Pap's account of the "functional a priori” was Cassirer's Determinismus und Indeterminismus in der modernen Physik (Cassirer 1937). DI was Cassirer's last great work in philosophy of science and appeared 1937 in his Swedish exile in German. Together with Substance and Function (Cassirer 1910), Einstein's Theory of Relativity (Cassirer 1921), DI should be recognized as an essential piece of Cassirer's Neo-Kantian philosophy of science. Another, more specific reason to take into consideration DI is that it helps understand Pap's early philosophy of science as put forward in FAP as a peculiar philosophical stance located somewhere between the currents of neoKantianism, pragmatism, and logical empiricism. Indeed, this is the main reason why DI is discussed in some detail in this paper.

The organization of this paper is as follows. To set the stage, in the next section, I briefly discuss the comments of some philosophers on Pap's philosophy of science. All of them show a certain perplexity of how to assess Pap's philosophical position. Critics of quite different philosophical perspectives agreed that the philosopher Pap was difficult to classify, although no one denied his logical and philosophical qualities and originality. Section 3 elaborates the intimate relations between Pap's early work and the later Cassirer's philosophy of science as presented in DI. In Section 4, I discuss in some detail Cassirer's “principles” of DI that play an important role for Pap's "functional a priori" elaborated in FAP. Moreover, I want to show that DI offers convincing arguments for correcting some widely accepted misconceptions of Cassirer's account of the a priori. Section 5 deals with the often-ignored pragmatic aspects of Cassirer's philosophy of science. Being already present in his first opus magnum Substance and Function (Cassirer 1910) they are further elaborated in DI. This aspect of Cassirer's work is relevant for assessing Pap's alleged move from Cassirer's Neo-Kantianism to Lewis's and Dewey's pragmatisms. In Section 6 I conclude with some speculations what could have happened with analytic philosophy in Europe if Pap's project of a

2 For the case of conventionalism, see Biagioli (2016, chapter 6), and for Cassirer's own rather positive assessment of the Vienna Circle's logical empiricism see Cassirer (2011). Cassirer's relation to pragmatism is discussed in some detail in Section 5 of this paper. 
"resuscitation of the Vienna Circle" in the early 1950s had not failed for unfavorable local circumstances.

\section{Pap's Philosophy of Science as a Maverick Account - Some Scattered Comments}

Let us begin by briefly discussing four or five scattered critical comments on Pap's philosophy that philosophers of quite different orientations put forward on quite different occasions for quite different purposes. These remarks do not yield a coherent picture of Pap's philosophy. On the contrary, at least some of them betray a deep-rooted insecurity of what to do with Pap's philosophy. It may be noted, however, that all of them either made short shrift or intended to play down any possible influence that Cassirer's neo-Kantian philosophy might have had on Pap.

The first author to be mentioned is Brand Blanshard. He is the author of a brief memoir of Pap that was published as an epilogue to Pap's last book An Introduction to the Philosophy of Science that appeared posthumously in 1962. Blanchard praised Pap as "one of the ablest younger philosophers of his generation" (Blanshard 1962, p. 427) describing his philosophical development as a journey from speculative beginnings with Hegel and Cassirer towards a soberer and more rational way of philosophizing somewhere in the neighborhood of logical empiricism. According to Blanchard, Pap, after having completed a master's degree under the supervision of Cassirer in Yale, soon "found that Cassirer's metaphysical speculation held little appeal for him", and went to Columbia and wrote a doctoral dissertation under the pragmatist and logical empiricist Ernest Nagel. A closer look on this dissertation, i.e., FAP, shows that Blanshard's neat "replacement thesis" (from European "Neo-Kantianism" to American Analytic Philosophy and pragmatism) is too simple to be true. This will be shown in the following sections.

The second philosopher of science I'd like to mention is Mary Hesse. In 1966 she wrote a review of An Introduction to Philosophy of Science (Pap 1962):

Philosophically speaking, Pap ... may be said to have been a logical empiricist with a bad conscience. [In his book [t]he scaffolding constructed by the Vienna Circle is everywhere visible, but Pap was far too intelligent, and far too competent in logic and mathematics, not to know that even the latter-day modifications forced upon this framework will not suffice to hold it up indefinitely. ...

Pap's strength does not lie in chiselling out from philosophy of science those fundamental philosophical questions which are beginning to come to light in a post-Vienna era. What he does very well is provide some of the elementary mathematical and logical tools which are and will remain indispensable to the philosopher of Science. (Mary Hesse 1966, p. 457). 
Hesse, engaged in elaborating her own, anti-Viennese account of a philosophy of science - based on the notions of model and analogy - criticized Pap's account as still being too much influenced by the allegedly obsolete Viennese logical empiricism. On the other hand, she felt that it would be somehow inadequate to characterize Pap simply as an ordinary logical empiricist. Hence, she took refuge to the rather cryptic characterization of Pap as a "logical empiricist with a bad conscience".

The next comment is from Paul Feyerabend. In his autobiography he wrote:

Arthur [Pap] had studied music and still excelled at the piano. After switching to philosophy, he worked with Cassirer and wrote a splendid essay on the a priori in physical theory (FAP, T.M). He then joined the analytic movement, made important contributions and published a textbook. Gradually he read less and wrote more; his writing became thin and unsubstantial. (Feyerabend 1995, pp. 99f)

This quotation suggests that Feyerabend considered FAP not as a work of analytic philosophy proper but as an opus related to Cassirer's neo-Kantian philosophy of science. Regrettably, Feyerabend never explained why he characterized Pap's later analytic writings as "thin and unsubstantial". Whatever he might have had in mind, it seems that also Feyerabend considered a characteristic feature of Pap's philosophy that it was localized somewhere "between" Neo-kantianism and "standard" analytic philosophy. ${ }^{3}$

Finally, I want to deal with some comments on Pap's life and work made by Alfons Keupink and Sanford Shieh, who edited Pap's Selected Papers that appeared in 2006. Arthur Pap already died in 1959 at the early age of 38. This is too young an age for a philosopher to become well-known outside a restricted circle of specialists. Hence, the short Intellectural Biography of Arthur Pap written by Keupink is quite useful for every scholar who is interested in Pap's work (cf. Keupink 2006).

After arriving with his family in 1941 in the United States, Pap settled in New York City. He started to study philosophy at Columbia University in the fall of 1941. After obtaining his B.A. at Columbia, he went to Yale University in 1943 for his master's degree. There, Cassirer became his supervisor and provided the original stimulus for Pap's work on hypothetical necessity and the functional a priori. In 1944 Pap returned to Columbia where he completed his PhD thesis The Functional A Priori in Physical Theory (FAP, Pap 1946) under the supervision of Ernest Nagel.

Sanford Shieh, the second editor of Pap's Selected Papers, contributes a detailed overview of Pap's philosophical work. From this text I'd like to quote the

3 Feyerabend's role in Pap's life was not restricted, however, to make these rather ephemeral comments on his philosophical evolution. For a short period in the 1950s he served as Pap's assistant at the University of Vienna and played a significant role in the publication of Pap's book Analytische Erkenntnistheorie. Kritische Übersicht über die neueste Entwicklung in USA und England (Pap 1955). We will deal with this episode of Pap's life in more detail in the last section of this paper. 
following remarks that resume some of the issues that already Hesse treated in her review of Pap (1962) some 40 years ago, adding to them a further twist:

\begin{abstract}
Mary Hesse once described Arthur Pap as a “logical empiricist with a bad conscience.” ..., this is true as far as it goes, but its emphasis is not quite right, nor does it go far enough. Much of Pap's bad conscience derives ... from allegiance to Cassirer's neo-Kantianism. Pap wouldn't give up this allegiance because he saw a deep tension in logical empiricism at its very best, namely, in the work of Carnap. The tension is between Carnap's adherence to the picture of rational inquiry underlying his continued insistence on an analytic-synthetic distinction, and his attempt to be thoroughgoingly pragmatic as manifested in his adoption of the Principle of Tolerance. (Shieh 2006, p. 43)
\end{abstract}

While Hesse had nothing to say about the causes of Pap's "bad conscience” Shieh offers sort of an explanation: He interprets Pap as a half-hearted critique of logical empiricism who was aware of the limits of this approach due to his continuing adherence to Cassirer's neo-Kantianism. He nowhere explains Pap's "allegiance with Cassirer" in any further detail, however, nor does he elucidate why Pap's continuing adherence to Cassirer's neo-Kantianism might have caused his discontent with Carnap's allegedly thoroughgoing pragmatism. Nevertheless, Shieh's cryptic remarks portends a basic problem for any interpretation of Pap's philosophy, namely, how it is related to the then contemporary currents of philosophy of science. Shieh's comments provide evidence that Pap's philosophy of science was a problem for virtually all philosophies of science. Somehow, Pap was sitting on the fence between various established philosophical currents such as Logical Positivism, American Pragmatism, and Neo-Kantian Critical philosophy. This is evident by the peculiar interpretation of Poincaré's famous characterization of "principles" that Pap chose as the motto of FAP:

Principles are conventions and definitions in disguise. They are, however, deduced from experimental laws, and these laws have, so to speak, been erected into principles to which our mind attributes an absolute value. (Foreword of FAP, vii, Poincaré 1906, p. 138)

For Pap, Poincaré's "principles” were closely related to Cassirer's Neo-Kantian "principles" in a peculiar way relating them with pragmatic and logical empiricist philosophemes:

It is one of the merits of the Marburg school of Neo-Kantianism to have disclosed the intimate connections between Kant's Critique, especially the Transcendental Analytic, and Newton's mechanics. ...

We shall now apply the functional theory of the a priori to such alleged synthetic a priori principles of Newtonian mechanics. These will be shown to be either functionally analytic at times referred to as "regulative principles", without foregoing, by this denomination, their claim to descriptive content - or inductive generalizations that have been transformed, in the 
process for formalization, into real definitions (factually grounded conventions), or, indeed, imperatives addressed to scientific procedure. (FAP, p. 39)

According to Pap, it would be a gross misunderstanding to take this interpretation as directed against logical empiricist philosophy of science according to which "all significant propositions are either analytic or empirical, such that no apodeictic knowledge of reality is possible". Rather, he assured the reader that [FAP] "presents ... a "supplementary emphasis" to the more standard logical positivists account. What this meant for Pap will be discussed in detail in the next section.

\section{DI and Pap's Philosophical Beginnings}

DI was Cassirer's last book on philosophy of science proper. It may be considered as the definite account of his theory of the relativized and historized a priori. The reception of DI among philosophers and physicists was rather mixed. Philipp Frank wrote a "generous" review that admitted that Cassirer was on the right track, but, "of course", he did not admit that the logical empiricists could learn anything from DI that they did not already know (cf. Frank 1938). Ernest Nagel's review was less friendly (cf. Nagel 1938). Although he applauded to "Professor Cassirer's great historical erudition as well as the insights characteristic of the Marburg NeoKantian movement" Nagel complained that DI did not offer anything "essentially new" that the reader didn't already know from Cassirer's earlier writings, in particular Substance and Function (Cassirer 1910). In sum, according to Nagel, there was only some "Kantian terminology and piety" in DI distinguished Cassirer's account from what "naturalistic pragmatists and logical empiricists could have written (cf. Nagel 1938, p. 230). ${ }^{4}$

In contrast to philosophers, physicists reacted quite positively to DI. As Thomas Ryckman reports, the physicists Einstein, Born, and von der Laue highly praised DI, although they did not review it (cf. Ryckman 2015, p. 86). When an English translation of DI posthumously appeared in 1956, the physicist Henry Margenau wrote an enthusiastic introduction and praised it as a visionary novel philosophical interpretation of quantum theory (cf. Margenau 1956).

These positive reactions did not prevent that DI played no important role in the Cassirer renaissance that took place in the last two decades. For example, Michael

4 In light of Nagel's dismissive review of DI it is hardly surprising that he rejected a first version of FAP. In this version, as is reported by Stump, Cassirer's influence was much more visible than in the final version (cf. Stump 2020, pp. 6ff). According to Pap's own harsh self-incrimination in the Acknowledgment of FAP, in his early years of philosophy he sometimes had succumbed to the vice of a metaphysical "pathos of obscurity" (FAP, Acknowledgement, v). 
Friedman does not treat DI neither in his influential Dynamics of Reason (Friedman 2001) nor in A Parting of the Ways. Carnap, Cassirer, and Heidegger (Friedman 2000), nor in Synthetic History Reconsidered (Friedman 2010) although Cassirer's philosophy occupies centre stage in all these works.

The critical attention that DI received in philosophy almost completely concentrated on the issue of the role that it ascribed to the venerable concept of causality after quantum theory had arrived on the scene in the 1920s (cf. Cei and French 2009; Pringe 2007, 2014; Ryckman 2015). For the topic of Pap's functional $a$ priori this was less important. Interesting for Pap was the more general, but less prominent topic of the general architecture of physical theories that was also dealt with in DI. The main novelty (compared with Substance and Function (Cassirer 1910) and Einstein's Theory of Relativity (Cassirer 1921) that Cassirer proposed in DI was the proposal that one should strictly distinguish between three types of statements of a physical theory:

1. Statements of results of measurements.

2. Statements of laws.

3. Statements of principles.

In Cassirer's terminology, statements of results of measurements are individual statements, statements of laws are general, and statements of principles are universal (cf. DI, p. 54). Cassirer insisted that the roles of these three types of statements were essentially different. Statements of results of measurements are only the first step in the transition from the realm of the given to the realm of scientific knowledge, or, in other words "from the world of sense to the world of physics (DI, p. 31)". They had to be complemented by statements of laws and by statements of principles. An important feature of this tripartition was that there did not exist a "continuous path" from one level to the other. Rather, the three levels were separated by conceptual discontinuities. Or, in Cassirer's own words, moving from one level to the other required a conceptual "jump“.

Cassirer considered it a fundamental conceptual error of logical empiricist philosophy of science that it did not recognize the discontinuity that existed between the three types of statements. Particularly harmful consequences followed if statements of laws were not distinguished from statements of principles, since thereby logical empiricism lost the conceptual means of adequately dealing with the evolution of scientific knowledge. This issue of evolution was, as is well known, an essential feature of scientific knowledge for the Marburg philosophy of science since its very beginning. Statements of principles are characterized in DI as follows: 
Principles are ... bold anticipations that justify themselves in what they accomplish by way of construction and inner organization of our total knowledge. They refer not directly to phenomena but to the form of the laws according to which we order these phenomena. A genuine principle, therefore, is not equivalent to a natural law. It is rather the birthplace of natural laws, a matrix as it were, out of which new natural laws may be born again and again. (DI, p. 53)

For Pap's philosophy, the discussions of Cassirer's interpretation of quantum theories were less important. After all, his early philosophical writings and, in particular, FAP only dealt with classical physics. More precisely, FAP dealt with the "application of the functional theory of the a priori to Newtonian mechanics" (FAP, Part 2). Pap's discussion of Cassirer's principles concentrated on what may be called the principle of continuity and other "geometrical" principles (cf. FAP, pp. $83 \mathrm{ff}) .^{5}$

Indeed, Pap's philosophical oeuvre began with an interpretation of the concept of principles as presented in DI. In his first published paper ever On the Meaning of Necessity (1943), Pap clearly stated that his functional a priori like Cassirer's principles of DI, expresses hypothetical necessities:

Such hypothetical necessities, or leading principles, bridge, so to speak, the gap between the contingency of empirical conjunctions and the "simple" necessity of formal connections, for they function essentially as means of systematizing facts, of rendering the body of factual knowledge coherent. It is by their instrumentality that facts acquire representative or signifying capacity, and thus evidential value. (Pap 1943, p. 49).

The functional a priori provided the means to overcome an overly simplistic positivist dichotomy:

\begin{abstract}
The positivistic - allegedly exhaustive - disjunction of judgments into empirical (contingent) and analytic (necessary) judgments takes no account of "synthetic a priori principles" which are, in Cassirer's words, "Regeln, gemäß deren nach Gesetzen zu suchen ist und nach denen diese zu finden sind". The empiricist walks on the plane of particulars and contemns the "high priori roads"; the rationalist walks on the "high priori roads" and contemns the plane of particulars. The functionalist, however, recognizes the functional correlation of plane and high-road: Die Höhenwege sind für unsere Orientierung in dem Gelände, das wir zu durchschreiten haben, unerläßlich.” (Pap 1943, p. 57)
\end{abstract}

To put it bluntly, in Pap (1943) the functional a priori was just another name for Cassirer's Höhenwege aka principles. The central role of DI's principles for Pap's

5 Following Reichenbach's Relativitätstheorie und Erkenntnis a priori (1920), Pap characterised these principles explicitly as constitutive principles (cf. FAP, chapter III). 
$\mathrm{FAP}^{6}$ has been rather ignored up to now. In FAP, Pap's formulations are a bit more cautious than in Pap (1943). He no longer prided himself to have overcome the "allegedly exhaustive" positivist disjunction of empirical (contingent) and analytic (necessary) judgements. Instead, he was content to claim for his functional theory no more than compatibility with the standard positivist or logical empiricist account in that the functional theory offers a "supplementary emphasis" to logical empiricism:

The present analysis [of FAP] ... in no way contradicts the positivistic working hypothesis [of logical empiricists that all significant propositions are either analytic or empirical]. It presents, however, a supplementary emphasis by focusing attention upon existential inquiry as the matrix of those "linguistic" conventions that give rise to analytic truth and upon the ways in which synthetic propositions function analytically without definitely assuming the status of "linguistic" conventions. (Pap 1946, pp. 40ff.)

Criticizing this passage as rather obscure one probably does not run a high risk to be blamed as someone who is excessively picky. On the contrary. This piece of Pap certainly does not serve as an example of crystal-clear analytic philosophy. In order to understand what Pap's intention was, it it necessary to go back to his earlier Meaning and Necessity (Pap 1943). There, he proposed the following, admittedly rather speculative, conflation of Kant, Cassirer, and Dewey as an elucidation of what he meant by the "supplementary emphasis" that he offered in FAP:

Cassirer tends to assimilate Kant's doctrine of the a priori to the functional-pragmatic interpretation of the a priori as a methodological rule: "Das a priori muß in rein methodologischem Sinne verstanden werden ... (Cassirer 1937, p. 93). ... [T] he typically Kantian conjunction of "a priori" with "synthetic" is essentially an attempt to overcome the dualistic separation of the $a$ priori and the empirical, and is thus opposed to the rationalistic identification of "a priori with "analytic" or "logically necessary". For the rationalists the "a priori" or "axiomatic" has intralogical significance, i.e., its meaning is not defined in terms of empirical application; which the "synthetic a priori" is synthetic insofar as it is essentially a prodedural means, to use Dewey's term, in existential inquiry. Insofar as it has no alternatives, it is, indeed axiomatic, "simply" necessary; insofar, however, as it is nothing but a conceptual tool of existential inquiry, a "universal” in Dewey's sense, it is hypothetically necessary. [Against Kant] [w] hat is a priori at one time, may have been a posteriori character at an earlier time; rules or criteria are themselves derived from, generated by, existence. Something is a priori, in other words, not simpliciter, but secundum quid, i.e., for one phase of the continuum of inquiry; it may be $a$ posteriori for another phase of the same. As Dewey puts it (cf. Dewey 1938, p. 14) Norms of inquiry are “operationally a priori with respect to further inquiry.” (Pap 1943, p. 53)

6 A telling example is Friedman's claim in Dynamics of Reason: "For Pap, in the end, what is functionally a priori is simply what is especially well confirmed or established, and in this way, Pap's approach is ultimately no different from Quine's appeal to entrenchment.” (DR, p. 88, Footnote 22). 
Not everybody will agree with Pap's conflation of the different, allegedly "pragmatic" a priori accounts put forward by Kant, Cassirer, and Dewey. The issue whether Pap's account is plausible or not, is not, however, to be discussed in the present paper. Rather, the point I want to make is that these quotations from FAP and earlier works of Pap suffice to recognize him unmistakenly as a philosophical child of Cassirer. It may well be the case that in later years this descendency is less visible. But this is the usual course of things. Moreover, Pap had very convincing, perhaps not purely philosophical reasons to play down Cassirer's influence. Indeed, Pap had to write two versions of his dissertation, because his supervisor Ernest Nagel required to revise the first version that he rejected as "too metaphysical”, i.e., as too openly influenced by Cassirer's neo-Kantianism. As Pap himself confessed he owed to Nagel's influence the "conversion from the metaphysical "pathos of obscurity" ... to conscientious endeavors of clear, rigorous thinking mainly to his philosophical influence" (FAP, v). ${ }^{7}$

Apart from issues of the philosophy of quantum theory DI has remained a rather neglected piece of Cassirer's philosophy of science. This has the regrettable consequence that also Cassirer's account of the a priori (as well as Pap's) is often misunderstood. An important consequence of such a misunderstanding for contemporary philosophy of science will be discussed in the next section.

\section{Cassirer's a priori in the Light of DI}

A closer look at DI is not only useful for understanding FAP, it may also help better understand Cassirer's philosophy of science in general, particularly his account of the $a$ priori. DI presents a concept of the a priori that is hardly compatible with the $a$ priori that is usually attributed to Cassirer stemming from his dispute with Moritz Schlick on the compatibility of Neo-Kantian philosophy of science with Einstein's theory of the relativity.

In light of the discovery of Non-Euclidean geometries and even more clearly in light of Einstein's theory of relativity, Cassirer and Neo-Kantian philosophy of science in general could not (and did not) stick to Kant's original conception of the a priori. For the Marburg Neokantians the problem arose to formulate a successor

7 A peak of such an "metaphysical pathos of obscurity" that probably Nagel disliked considerably, can be found in Pap (1944) where he - although with some hesitation - subscribed to Hermann Cohen's account of "Bewußtsein überhaupt" as the subject matter of Kantian "transcendental logic". Already then, he pointed out that some may "dislike the notion of "Bewußtsein überhaupt" because of its metaphysical "pathos of obscurity" (Pap 1944, p. 69). On the "asymmetrical" influence of Nagel and Cassirer on Pap, see Stump (2020, pp. 6ff). 
concept of the Kantian a priori that preserved at least partially the "Kantian spirit" of the original concept and that, at the same time, could cope with the challenges put forward by post-Kantian science.

As is well known, Kant's a priori had both regulative and constitutive aspects. A crucial problem for a modernized concept of the a priori was whether this duality between the regulative and the constitutive could be preserved in one way or other. Cassirer's a priori has often been criticized to fail in this respect. For instance, Friedman asserts: "Cassirer's conception of the a priori is purely regulative, with no remaining constitutive elements." (Friedman 2001, p. 60, footnote 80 ). ${ }^{8}$ A closer look on Cassirer's text of 1921, however, reveals that Friedman's claim is mistaken. Cassirer's a priori is not purely regulative, it also has constitutive ingredients, or so I want to argue: A contentful constitutive a priori is present already in Cassirer's treatise on relativity theory (Cassirer 1921) - the "theory" of such a constitutive $a$ priori is most explicitly formulated in DI. This is not to say that such a theory was to be considered as a completely new ingredient of Cassirer's thought. Cassirer claimed that this theory was fully in line with the account of the a priori formulated almost 30 years earlier in Substance and Function (Cassirer 1910).

Although many philosophers of science have considered Friedman's thesis that Cassirer's a priori was purely regulative as convincing, I want to show that Friedman is wrong. Actually, Cassirer's concept of the a priori is richer and less shallow than is often thought. This can be seen by looking more carefully on Cassirer (1921) and by taking into account the role of "principles" that Cassirer offered in DI. This requires a detailed interpretation of the relevant texts.

According to Friedman, already Schlick in his well-known critical review of Cassirer's Einstein's Theory of Relativity (Cassirer 1921) recognized that Cassirer's a priori was purely regulative. In Friedman (2000) he reports Schlick's contention as follows:

[Cassirer's] a priori of space ... does not include ... any assertion about a determinate particular structure of space, but is concerned only with the function of "spatiality in general" ... entirely without regard to its more particular determination. (Schlick 1921, p. 101; Friedman 2000, p. 115, Footnote)

For Schlick, and still for many contemporary philosophers of science as well, this quotation conclusively showed that Cassirer, confronted with Einstein's theory, subscribed to a purely regulative a priori that many (not Friedman himself)

8 In contrast, Friedman claims, his own conception of a relativized a priori, preserves a constitutive component: The present conception (of Friedman, T.M.) results from combining the relativized yet still constitutive a priori developed within the logical empiricist tradition with the Marburg version of the regulative use of reason (Friedman 2001, p. 60, footnote 80). 
considered as rather trivial and useless. Actually, Cassirer's a priori in Cassirer (1921) is not solely regulative. Schlick and Friedman's quotation is misleading and does not convey what Cassirer actually asserted in his book: The complete quote reads as follows:

[T]he "a priori” of space that [critical Erkenntnistheorie] affirms as the condition of every physical theory involves ... no assertion concerning any definite particular structure of space in itself, but is concerned only with that function of "spatiality" in general, that is expressed already in the general concept of the line element ds as such, entirely without regard to its character in detail (my underlining, T.M.). (Cassirer 1921, p. 101, 1923, p. 433).

From the German original, it transpires that the phrase "without regard to its character in detail" does not refer to "spatiality in general", but to "line element". 9 This is rendered completely clear from the text that immediately follows:

If ... the determination of this element (i.e., the line element ds, T.M.) as it is done in Euclidean geometry, does not suffice for the mastery of certain problems of knowledge of nature then nothing can prevent us, from a methodological standpoint, from replacing it by another

9 The German original reads as follows: "Denn das "A priori" des Raumes, das sie ( = criticial theory of knowledge) als Bedingung jeder physikalischen Theorie behauptet, schließt, wie sich gezeigt hat, keine Behauptung über eine bestimmte einzelne Struktur des Raumes in sich, sondern geht nur auf jene Funktion der „Räumlichkeit überhaupt“, die sich schon in dem allgemeinen Begriff des Linienelements ds als solchen - ganz abgesehen von seiner näheren Bestimmung ausdrückte.“ The possessive pronoun "seiner” in the phrase "seiner näheren Bestimmung” unambiguously indicates that this phrase refers to "Linienelement", and not to "Räumlichkeit überhaupt." This shows that Cassirer's a priori of space as a "condition of every physical theory" is the a priori of Riemannian geometry encapsulated in the concept of the (Riemannian) line element ds. This a priori is more general than the traditional Euclidean a priori (that amounts that Riemannian curvature $\mathrm{K}$, defined by ds, is 0 ), but it is still a contentful constitutive $a$ priori.

In his most recent contribution to the issue of the a priori Friedman points out that Schlick is wrong in blaming Cassirer not to delineate in any way the content of his alleged a priori of "spatiality in general". He makes clear that Cassirer's a priori of "spatiality in general" refers to Riemannian geometry. As Friedman rightly points out Riemannian geometry certainly is a very non-trivial and contentful a priori principle. Riemannian geometry is not just a cheap generalization of Euclidean geometry in the sense that for the more general Riemannian geometry curvature is allowed to be a variable (instead of being the constant 0), but Riemannian geometry amounts to a considerable "lowering of the foundations" as Cassirer used to say (following Hilbert). Thus, Riemannian geometry was, for Cassirer the best then available approximation of a universal invariant of physical knowledge. According to Friedman, the general character of Riemannian geometry (compared with Euclidean geometry) deprives it of all constitutive features and renders it a purely regulative a priori (Friedman 2010, p. 683). Not everybody agrees: Heis considers Riemannian geometry as constitutive and regulative (see Heis 2014, p. 14). Relying on Cassirer's DI, it seems that this ecumenical stance is the most congenial attitude to this issue. Also, for Richardson 2010), the central difficulty of Cassirer's concept of the a priori resides in the relation between its constitutive and regulative moments. 
measure, in so far as the latter proves to be necessary and fruitful physically ... (Cassirer 1921, p. 101, 1923, p. 433).

Thus, in Einstein's Theory of Relativity (Cassirer 1921) Cassirer maintained a highly non-trivial constitutive spatial a priori, namely, the Riemannian structure of spacetime encapsulated in the Riemannian line element ds.

Many philosophers of science do not accept Friedman's thesis. For instance, Thomas Ryckman argued that for Cassirer the principle of general covariance was an important a priori principle that was both constitutive and regulative (Ryckman 2005, chapter 2.5, pp. 40ff). Krois, more recently, claimed that according to Cassirer the concept of "symbolic pregnancy" is a constitutive and not only regulatory $a$ priori in the cultural sciences (cf. Krois 2010, p. 267). Somewhat differently, Richardson has argued that Cassirer (unsuccessfully) attempted to formulate "a transcendental logic of objective knowledge" that embraced constitutive and regulative elements (cf. Richardson 2010, chapter 5). ${ }^{10}$ Perhaps the most comprehensive account of Cassirer's theory of the a priori has been put forward by Heis in Realism, functions, and the a priori: Ernst Cassirer's philosophy of science (Heis 2014), who argues that Cassirer's theory of the a priori comprises constitutive and regulative, as well as absolute and relativized aspects without falling into inconsistency (cf. Heis 2014). This paper is not the appropriate place to enter into this multifaceted debate in any detail. The only point I want to make is that, somewhat surprisingly, none of the protagonists of the ongoing discussion has paid much attention to what Cassirer said on this issue in DI, in particular, in his theory of "principles". Taking into account the "principles" of DI is evidence that Cassirer - at the end of his career as a philosopher of science - indeed conceived the $a$ priori in a constitutive and regulative way. That the regulative and the constitutive function as complementary aspects of his a priori becomes clearer if DI's principles are taken into account. In the metaphorical language of DI Riemannian geometry becomes "a matrix out of which new natural laws may be born again and again".

Back to Pap. Instead of the metaphorical term "matrices" Pap in FAP and in his earlier papers often characterized "matrices" simply as leading principles or as methods that guide the praxis of scientists.

In FAP and his other writings Pap did not deal with Riemannian geometry, but mainly with the more elementary a priori principles of Newtonian physics, for instance, the spatial and geometrical a priori assumptions that assert that empirically meaningful functions have to be "continuous", and every magnitude that

10 In Richardson (2010) the author proposes to clarify the relation between the constitutive and the regulative a priori by invoking the complementarity between Hegelian and Kantian aspects in Cassirer's (and Friedman's) thought (cf. Richardson 2010, p. 288). 
that is to be interpreted as "force" has to satisfy the laws of vector calculus. According to Pap, Newtonian physics had to assume a considerable amount of classical mathematics as a constitutive a priori. Without taking into consideration the theory of principles put forward in DI, Cassirer's conception of the a priori is misunderstood. The same holds for Pap's functional a priori that rather faithfully follows Cassirer's account.

Stump rightly remarks that the purely regulative a priori that Schlick and Friedman ascribe to Cassirer is untenable:

\footnotetext{
What we actually use in science is our current understanding of concepts, not what the concepts ... will be at the hypothetical end of inquiry. The understanding of the concepts that we actually use in science do change from one historical period to another and therefore the supposedly universal and fixed elements of the a priori vanish. If we look at science as it is actually practiced, as I think we must, there are no universal and fixed concepts in science, given that the understanding of the fundamental concepts changes over time. (Stump 2015, p. 94)
}

Stump is certainly right in pointing out that ghostly concepts like "spatiality in general" are hardly relevant for real science. The point is that a "purely regulative Cassirer" who allegedly endorsed such concepts is not the real Cassirer. DI shows that Cassirer's a priori was not so anemic as Schlick, Friedman, and many others want to make us believe. The development of modern mathematical physics has amply demonstrated that the mathematical theory of Riemannian geometry is justly characterized as a regulative and constitutitve a priori principle that has turned out to be an immensely fruitful matrix for a wealth of theoretical and practical physical knowledge.

\section{Cassirer's "Theoretical Pragmatism"}

Cassirer was not a narrow-minded orthodox Neo-Kantian. Throughout his career he was open for many philosophical and scientific influences. In this section, I'd like to argue more specifically that some kind of "theoretical pragmatism" may be attributed to him since the beginnings of his systematic philosophy of science in Substance and Function (1910). This is relevant for an adequate interpretation of Pap's philosophy of science, since thereby a simplistic periodization of influences on Pap's philosophy à la “first characterized by Cassirer's neo-Kantianism, then influenced by Dewey's and Lewis's pragmatism, and finally by Carnap's logical empiricism” is rendered not very convincing. In particular, American pragmatism and European neo-Kantianism as influences on Pap's philosophy should not be played off against each other. 
A pragmatic component in Cassirer's philosophy of science is encapsulated in the claim that "valid" concepts contain "plans for possible constructions of unity". Concepts are not descriptions of facts but blue prints for further experiences:

"[Scientific] concepts are valid, not in that they copy a fixed, given being, but in so far as they contain a plan for possible constructions of unity which must be progressively verified in practice, in application to the empirical material. ... We need, not the objectivity of absolute things, but rather the objective determinateness of the method of experience. (Cassirer 1910, p. 322).

Pragmatic aspects of Cassirer's philosophy of science are already present in Cassirer's early philosophy of science, i.e., in his Substanzbegriff und Funktionsbegriff (1910). There he emphasized the affinity of his "Critical Idealism” with Dewey's and James’s pragmatisms (cf. Cassirer 1910, chapter VII). He pointed out that a sophisticated version of pragmatism such as Dewey's (to be distinguished from the vulgar versions of this doctrine) was fully in line with his Neo-Kantian own "critical idealist" account of knowledge. ${ }^{11}$ More precisely, he argued that Dewey's pragmatism, correctly understood, was concerned with the relation between the objectively valid propositions of science and the activity of thought:

[T]hought has here become the pure and complete expression of "doing”.... Our inferences and conclusions, our investigations and experiments are "practical" ... in the sense that it is the unity of all thought, which stands constantly before us as an ultimate goal and directs out cognition.... Each hypothesis of knowledge has its justification merely with reference to this fundamental task; it is valid to the degree that it succeeds in intellectually organizing and harmoniously shaping the originally isolated sensuous data. (Cassirer 1910, p. 344, 1923, p. 318)

Thus, from early on, pragmatic considerations were not totally alien to Cassirer's thought. For the early Pap, as a student of Cassirer's, that meant that he needed not break with his master's doctrines to acquire a liking for pragmatism. Already in Pap 1943 and Pap 1944 Pap emphasized the role of pragmatic considerations in the formulation of the functional a priori, often quoting Dewey's Logic-The Theory of Inquiry (Dewey 1938). Thus, Pap's reliance on American pragmatism should not be taken as an aspect of his thought that was added more or less artificially later and replaced his Neo-Kantian traits. For instance, in Pap 1943 he interprets Cassirer as a neo-Kantian "who tends to assimilate Kant's doctrine of the a priori to the functionalpragmatic interpretation of the a priori", thereby approaching Dewey's concept of an "operationally a priori with respect to further inquiry" (Dewey 1938, p. 14; Cassirer

11 This is not to say, of course, that Cassirer can be characterized simply as a pragmatist without qualifications. For a detailed and still readable account of the similarities and dissimilarities of Cassirer's and Dewey's accounts of knowledge, see Kaufmann (1949).

For a discussion of the relation between Cassirer's and Dewey's general "philosophical projects" see Freyberg and Niklas (2018). 
1937, p. 93). He even voiced the concern that Cassirer's reading of Kant might be more pragmatist than was permitted to a faithful Kantian (Pap 1943, p. 53). In any case, for Pap, the Neo-Kantian Cassirer of DI and the pragmatist Dewey of Logic 1938 went well together (cf. also Stump 2015, pp. 104ff.). In sum, Pap's pragmatic account of the functional a priori is quite similar to Cassirer's "Neo-Kantian" account. FAP and Cassirer's late Neo-Kantian philosophy of science of DI may be characterized as two kindred pragmatistically influenced neo-Kantian philosophies of science.

Taking into account the influence of DI evidences that Pap's functional a priori went beyond a "hardening" of "empirical facts" to yield pragmatically a priori definitions. Pap's functional a priori also includes the aspect of the a priori as a guiding and generating principle that plays a central role in the evolution of scientific knowledge.

It was a basic tenet of the Marburg Neo-Kantian philosophy of science that scientific concepts are always preliminary concepts to be replaced by better and more sophisticated ones in the course of the evolution of science, or, expressed in the well-known dictum of Cassirer's Marburg colleague Paul Natorp "Science is a fact in becoming (Werdefaktum)". This entails, as both Cassirer and Pap emphasized, that principles are not fixed once and for all. Rather, they evolve in the history of science proper. As essential factors of the evolution of science, they are not to be characterized as a lofty piece of philosophical speculation dealing in an abstract way with the epistemology or methodology of a scientific theory. Rather, they are to be characterized as integral ingredients of scientific knowledge. For Cassirer, this amounted to a kind of pragmatic dialectic of science:

Knowledge of fact and knowledge of principle ... are correlative.... The more the structure of science develops, and the more sophisticated it becomes, the more it requires proof, and continual renewal, of its basis. It belongs to the very essence of every science, according to Hilbert, that a "lowering of the foundations" must accompany the influx of new facts. If this is true, it is also clear that, and why, the work of discovering and establishing the principles of the individual sciences cannot be transferred to a particular philosophical discipline, be it “epistemology” or methodology (Cassirer 1942, pp. 63ff.).

In sum, FAP and Pap's earlier papers may be read as attempts to show that this neoKantian perspective was compatible with Dewey's pragmatist conception of the development of scientific knowledge.

\section{Concluding Speculations}

In the "Call for Papers" for the conference Cassirer's Children the organizers Massimo Ferrari and Sebastian Luft invited the prospective participants to speculate that 
the history of 20th century philosophy "might have turned out quite differently had Cassirer lived long enough in the United States to establish a pool of students. They might have shaped the face of philosophy differently. ... Indeed, it is not too far-fetched to say that, with the presence of a balancing figure such as Cassirer, the hostile standoff between "continental" and "analytic" philosophy, which has polarized the scene since, might have altogether turned out less hostile or even would not have existed....

This hopeful speculation is in stark contrast with Michael Friedman's pessimistic assessment of any possible relation between continental and analytic philosophy "after 1933". According to Friedman, the clash between "the analytic" and the “continental tradition" had become irreconcilable:

The thoroughgoing intellectual estrangement of these two traditions, their almost total lack of mutual comprehension, is a product of the National Socialist seizure of power in 1933 and the resulting intellectual migration. Before this ... logical positivism, as represented by Carnap, was very actively engaged with the other vocal movements in the German-speaking philosophical scene - with neo-Kantianism, with Husserlian phenomenology, and even with the "existential hermeneutic" variant of phenomenology then being developed by Heidegger. (Friedman 2000, p. 156)

Friedman's pessimistic assessment directly contradicts the very existence of people such as Arthur Pap or Susanne Langer, who long "after 1933” pursued a philosophy that aimed to overcome the notorious gap between the continental and the analytic tradition.

Moreover, it may well be doubted that "1933" was the point of no-return that rendered impossible even for well-intentioned partisans of logical positivism such as Carnap to maintain a distanced but respectful interest to continental movements of philosophy. In particular, one may doubt that until 1933 Carnap was "very actively engaged with non-logico-empiricist philosophical movements in Germany". For instance, the often-told pathetic story that Carnap and Heidegger discussed with each other in Davos is based on a confusion of the abbreviation of names. Further, Carnap's relation with Husserlian phenomenology had ended in dissonance long before 1933 for philosophical discrepancies quite unrelated to the Nazis' seizure of power. Similarly, the relation between Cassirer and the Vienna Circle was rather one-sided. Although Cassirer was earnestly interested in the work of logical empiricists, as is convincingly evidenced by his Nachlass (cf. Cassirer 2011), no analogous activity can be reported from the members of the Vienna Circle logical empiricists.

Thus, the following not-so-well-known episode of the 1950s may be especially interesting in which Arthur Pap played a central role. Under more fortunate circumstances, it could have contributed to overcome the "estrangement" between the two traditions even after WW2. Everything started with a strange post mortem 
afterlife of the Vienna Circle. The original Vienna Circle had been dissolved in the early 1930s. Carnap and Neurath had emigrated to US and England, respectively, and with the murder of Schlick in 1936 the Circle ceased to exist. Or almost so. Some not so well-known members of the circle stayed in Austria, surviving the "Anschluss" in 1938 and the war. One of them was Victor Kraft. When the war had ended, Kraft gathered in the early 1950s a group of philosophers and scientists that aimed to re-stablish in Austria that kind of philosophy that had flourished in Vienna before the original Circle was dissolved by the Catholic Fascists in the early 1930s. Today, Kraft's discussion group is sometimes referred to the "Third Vienna Circle” (Stadler 2010, p.70).

A member of this group was the young Paul Feyerabend. Moreover, Kraft invited Arthur Pap as a guest professor to the University of Vienna in 1953/54. There he lectured in German on Analytic theory of knowledge. Paul Feyerabend served as Pap's assistant and wrote down and elaborated Pap's lectures (cf. Feyerabend 1995, p. 99). ${ }^{12}$ In 1955 they were eventually published in German as the book

\section{Analytische Erkenntnistheorie. Kritische Übersicht über \\ die neueste Entwicklung in USA and England.}

The book had the programmatic dedication:

\section{Dem “Wiener Kreis” zum Andenken und zur Wiederbelebung}

As already Blanshard pointed out in his memoir on Pap (see Blanshard 1962), the young Pap was considered by many philosophers, not only in Austria by the partisans of the so called "Kraft Circle", but in many other European countries as well as competent representative of analytic philosophy. He was asked to lecture at Uppsalla and Copenhagen, Oxford and Cambridge. For some time, Pap was even seriously interested in continuing his career at the University of Vienna.

One can only speculate what would have happened, if he had obtained this position in Vienna, had not passed away prematurely, and thereby had made a contribution to establish in Vienna a philosophy that took into account the best components of the analytical and the Continental tradition.

12 The present paper is not the appropriate place to deal with Pap's and Feyerabend's relation in Vienna in detail. Interesting information on this issue can be found in the correspondence between Feyerabend and Popper (see Collodel and Oberheim 2020) as well as in Pap's correspondence with philosophers such as Carnap, Hempel, Nagel, and Quine accessible from the Arthur Pap Archives at the University of Vienna. 
For some unclear reasons, however, his attempts were thwarted by a member of the philosophical department of the University of Vienna and he did not succeed to obtain a permanent position in Austria and returned to the USA (Stadler 2010, p. 174). Thus, Pap did not play significant role in the return of Wissenschaftsphilosophie to the German-speaking countries after WW2. This role was to be taken by another member of the Kraft Circle, namely, the Austrian Wolfgang Stegmüller.

Pap's Analytische Erkenntnistheorie was not the only and not even the first book in German that was published after the end of WWII that intended to inform the German-speaking audience about the philosophical developments that had taken place in the Anglo-Saxon world after 1933. Already in 1952, Wolfgang Stegmüller had published Hauptströmungen der Gegenwartsphilosophie (Stegmüller 1952) whose longest chapter of more than 100 pages dealt with "Logical Positivism: Rudolf Carnap and other representatives of the Vienna Circle”. While Pap's book did not find much attention in the following years, Stegmüller's book became a kind of philosophical longseller and a main source of information for a German-reading public interested in Anglo-Saxon analytic philosophy. ${ }^{13}$ But also Stegmüller had no success in Vienna. A few years later, the philosophy department of the Vienna university also impeded that Stegmüller obtained a permanent position in Vienna. Instead, Stegmüller obtained a chair in Munich, becoming there the head of the rather successful Münchner Schule that played a major role in the return of analytic philosophy to Germany after WW2.

In sum, Pap's stay in Vienna remained an episode that had no lasting effects on the issue of a possible comeback of analytic philosophy and philosophy of science to the German-speaking countries after WW2. ${ }^{14}$ Thus, Pap's short stay in 1953/54 in Vienna may be considered as a missed opportunity for a new beginning

13 This is not the place to deal with Stegmüller's Hauptströmungen in detail (cf. Damböck 2010, Mormann 2010). Be it sufficient to say that Pap's and Stegmüller's philosophical styles were quite different: Although Stegmüller's opus experienced many re-editions, extensions and enlargements well into the 1980s, his author never felt the inclination to allow any neo-Kantian or pragmatist thinker to enter his canon of Hauptströmungen der Gegenwartsphilosophie (Main currents of contemporary philosophy). Instead, well into the ultimate editions of Hauptströmungen in the 1980s the reader finds the original chapters of the 1950s edition treating Robert Reininger's “Transcendental Idealism”, Paul Häberlin's “Universal Ontic Monism” etc. simply juxtaposed with the already mentioned chapter on "Logical positivism: Rudolf Carnap and other representatives of the Vienna Circle".

14 Only much later, Vienna played a positive role in the preservation of Pap's philosophical heritage. As a kind of belated posthumous correction of Pap's rejection in the 1950s by the institutionalized Viennese philosophy one may interpret the fact that in 2012 the Institute Vienna Circle (founded in 1991) became the home of the Arthur Pap archive where Pap's posthumous papers are stored and have been rendered accessible for academic research. 
for European philosophy of science after WW2. In other words, it seems not too far fetched to conjecture that under more favorable circumstances Pap could have served as a mediator between the "analytic" and "continental" tradition thereby overcoming the dogmatic dualism of these two philosophical currents that has characterized philosophy in the second half the 20th century.

\section{References}

Biagioli, F. 2016. Space, Number, and Geometry from Helmholtz to Cassirer. Berlin: Springer. Blanshard, B. 1962. "Epilogue: A Memoir." in Arthur Pap, an Introduction to the Philosophy of Science. Glencoe, Illinois: The Free Press.

Cassirer, E. 1910. Substanzbegriff und Funktionsbegriff, Untersuchungen über die Grundfragen der Erkenntniskritik. Hamburg: Verlag Felix Meiner. Translated as Substance and Function, Chicago, Open Court, 1923.

Cassirer, E. 1921. Zur Einsteinschen Relativitätstheorie. Berlin: Bruno Cassirer. Translated as Einstein's Theory of Relativity, Chicago, Open Court, 1923.

Cassirer, E. 1937. Determinismus und Indeterminismus in der modernen Physik. Göteborg: Högskolas Arsskrift. 42. Translated as Determinism and Indeterminism in Modern Physics. New Haven, Yale University Press, 1956.

Cassirer, E. 1942. Zur Logik der Kulturwissen-schaften, Fünf Studien, Göteborgs Högskola Arsskrift XLVIII. Translated into English as The Logic of the Cultural Sciences: Five Studies by S. G. Lofts. New Haven: Yale University Press 2000.

Cassirer, E. 2011. Symbolische Prägnanz, Ausdrucksphänomen und „Wiener Kreis“, Nachgelassene Manuskripte und Texte Band 4. Hamburg: Verlag Felix Meiner.

Cei, A., and S. French. 2009. "On the Transposition of the Substantial into the Functional: Bringing Cassirr's Philosophy of Quantum Mechanic into the 21st Century." In Constituting Objectivity, Transcendental Perspectives on Modern Physics, edited by M. Bitbol, P. Kerszberg, and J. Petitot, 95-115. Berlin: Springer.

Collodel, M., and E. Oberheim. 2020. Feyerabend's Formative Years, Vol. 1, Feyerabend and Popper, Correspondence and Unpublished Papers (eds.), 5. Cham, Switzerland: Springer.

Damböck, C. 2010. “Wolfgang Stegmüller und die „kontinentale Tradition“: zur Entstehung und Konzeption der "Hauptströmungen der Gegenwartsphilosophie“.” In Vertreibung, Transformation und Rückkehr der Wissenschaftstheorie: Am Beispiel von Rudolf Carnap und Wolfgang Stegmüller, edited by F. Stadler (Hrg.), 253-70. Berlin und Wien, LIT Verlag.

Dewey, J. 1938. Logic, the Theory of Inquiry. New York: H. Holt.

Feyerabend, P. K. 1995. Killing Time, the Autobiography of Paul Feyerabend. Chicago: The University of Chicago Press.

Frank, P. 1938. “„Bemerkungen zu E. Cassirer, Determinismus und Indeterminismus in der modernen Physik“, Theoria 4, 70, Göteborg. Translated as Determinism and Indeterminism.” In Modern Science and its Philosophy, edited by Ph.Frank, 172-85. New York: George Braziller.

Freyberg, S., and Niklas, S. 2018. "Rekonstruktive Synthesis. Zur Methodik der Kulturphilosophie bei Ernst Cassirer und John Dewey." In Ernst Cassirer in Systematischen Beziehungen. Zur 
kritisch-kommunikativen Bedeutung Seiner Kulturphilosophie, edited by T. Breyer, and S. Niklas (Hrg.), 47-68. Berlin: de Gruyter.

Friedman, M. 2000. A Parting of the Ways. Carnap, Cassirer, and Heidegger. Open Court: Chicago and LaSalle.

Friedman, M. 2001. Dynamics of Reason, the 1999 Kant Lectures at. Stanford/California: Stanford University, CSLI Publications.

Friedman, M. 2010. "Synthetic History Reconsidered." In Discourse on a New Method.

Reinvigorating the Marriage of History and Philosophy of Science, edited by M. Domsky, and M. Dickson, 571-812. Open Court: Chicago and LaSalle.

Heis, J. 2014. "Realism, Functions, and the A Priori: Ernst Cassirer's Philosophy of Science."

Studies in History and Philosophy of Science 48: 10-19.

Hesse, M. 1966. "Review of Arthur Pap, An Introduction to the Philosophy of Science." Mind 75: 456-7.

Kaufmann, F. 1949. “Cassirer's Theory of Knowledge.” In The Philosophy of Ernst Cassirer, edited by P.A. Schilpp, 183-213. Evanston, Illinois: The Library of Living Philosophers Inc.

Keupink, A. 2006. “Arthur Pap (1921-1959), A Brief Intellectual Biography.” In The Limits of Logical Empiricism, Selected Papers of Arthur Pap, edited by A. Keupink, and S. Shieh, 365-8. Dordrecht: Springer.

Krois, J. 2010. "Validity in the Cultural Sciences?." In Discourse on a New Method. Reinvigorating the Marriage of History and Philosophy of Science, edited by M. Domsky, and M. Dickson, 261-78. Open Court: Chicago and LaSalle.

Margenau, H. 1956. "Preface by Henri Margenau." In Determinism and Indeterminism in Modern Physics, edited by Ernst Cassirer, ix-xx. New Haven: Yale University Press.

Mormann, T. 2010. "Wien und München: Zwei Stationen der deutschsprachigen Wissenschaftsphilosophie im 20. Jahrhundert." In Vertreibung, Transformation und Rückkehr der Wissenschaftstheorie. Am Beispiel Rudolf Carnap und Wolfgang Stegmüller, edited by F. Stadler (Hrg.), 341-370. Berlin, Wien, Lit Verlag.

Nagel, E. 1938. "Review of Ernst Cassirer, Determinismus und Indeterminismus in der modernen Physik." Philosophy of Science 5 (2): 230-2.

Pap, A. 1943. "On the Meaning of Necessity." In The Limits of Logical Empiricism, Selected Papers of Arthur Pap, 47-55. Dordrecht: Springer.

Pap, A. 1944. "The Different Kinds of the A Priori." In The Limits of Empiricism, Selected Papers of Arthur Pap, 57-75. Dordrecht: Springer.

Pap, A. 1946. The A Priori in Physical Theory. New York: King's Crown Press.

Pap, A. 1955. Analytische Erkenntnistheorie. Kritische Übersicht über die neueste Entwicklung in USA und England. Wien: Springer.

Pap, A. 1958. Semantics and Necessary Truth: An Inquiry into the Foundations of Analytic Philosophy. New Haven, CT: Yale University Press.

Pap, A. 1962. "An Introduction to the Philosophy of Science." New York: Free Press of Glencoe.

Poincaré, H. 1906. La Science et l'Hypothèse. Paris: Flammarion. Translated by W. Greenstreet as Science and Hypothesis, London, Scott.

Pringe, H. 2007. "Critique of the Quantum Power of Judgment.” Kantstudien Ergänzungshefte 154.

Pringe, H. 2014. "Cassirer and Bohr on Intuitive and Symbolic Knowledge in Quantum Physics." Theoria 29 (3): 417-29.

Reichenbach, H. 1920. Relativitätstheorie und Erkenntnis a priori. Berlin: Springer.

Richardson, A. 2010. "Ernst Cassirer and Michael Friedman: Kantian or Hegelian Dynamics of Reason?." In Discourse on a New Method. Reinvigorating the Marriage of History and 
Philosophy of Science, edited by M. Domsky, and M. Dickson, 279-94. Open Court: Chicago and LaSalle.

Ryckman, T. 2005. The Reign of Relativity: Philosophy in Physics: 1915-1925. New York: Oxford University Press.

Ryckman, T. 2015. "A Retrospective View of Determinism and Indeterminism in Modern Physics." In The Philosophy of Ernst Cassirer, edited by J.T. Friedman, and S. Luft, 65-102.

Shieh, S. 2006. “Introduction." In The Limits of Empiricism, Selected Papers of Arthur Pap, 3-43.

Stadler, F. 2010. "History of the Philosophy of Science. From Wissenschaftslogik (Logic of Science) to Philosophy of Science: Europe and America, 1930-1960." In Vertreibung, Transformation und Rückkehr der Wissenschaftstheorie. Am Beispiel Rudolf Carnap und Wolfgang Stegmüller, edited by F. Stadler (Hrg.). Berlin, Wien, Lit Verlag, 9-84.

Stegmüller, W. 1952. Hauptströmungen der Gegenwartsphilosophie. Wien, Stuttgart: Humboldt Verlag.

Stump, D. 2015. Conceptual Change and the Philosophy of Science. Alternative Interpretations of the A Priori. New York: Routledge.

Stump, D. 2020. “The Kantian Elements in Arthur Pap's Philosophy.” Journal of Transcendental Philosophy: 1-13. 